American J. of Engineering and Applied Sciences 4 (3): 355-362, 2011

ISSN 1941-7020

(C) 2014 M.Z. Abdullah et al., This open access article is distributed under a Creative Commons Attribution

(CC-BY) 3.0 license

\title{
Optimization of Energy Dispersive X-Ray Fluorescence Spectrometer to Analyze Heavy Metals in Moss Samples
}

\author{
${ }^{1}$ Mohd Zahari Abdullah, ${ }^{3}$ Ahmad Saat and ${ }^{2}$ Zaini Hamzah \\ ${ }^{1}$ Department of Chemistry, Faculty of Applied Sciences, \\ University Technology MARA, Kampus Pahang 24600, Malaysia \\ ${ }^{2}$ Department of Chemistry, Faculty of Applied Sciences, \\ University Technology MARA, 40450 Shah Alam, Malaysia \\ ${ }^{3}$ Institute of Science, University Technology MARA, 40450 Shah Alam, Malaysia
}

\begin{abstract}
Problem statement: Mosses had been widely used as bioindicator especially to study the levels of trace metals pollutants in the surrounding ambient air because of their high efficiency to accumulate heavy metals contamination. There had been increasing demand to get a suitable analytical tools to determine the chemical contents of moss samples in this type of media. This study was conducted with the aims to get one of the best analytical methods for the analysis of moss samples. Approach: Despite the various spectroscopic techniques that normally used to analyzed heavy metals in moss, each of these techniques had its advantages and disadvantages which been summarized elsewhere. We try not to use any chemical to decompose the samples where the samples were analyzed directly in its solid form by Energy Dispersive X-Ray Fluoresence Spectrometer, EDXRF technique. The EDXRF technique optimized for its main analytical parameters. Calibration procedure was made based on the in-house standard samples. The reliability of the optimized analytical procedure was established by analyzing two certified reference materials, Pine Needle, NIST 1575 and Lichen, IAEA336. Results: The results showed that the metals could be analyzed with percent recoveries range within $84-102 \%$ for Pine Needle and $92-125 \%$ for Lichen. The possible factors influencing the percent recoveries of the elements were discussed in details. Conclusion: On overall, it is strongly suggest that the applied EDXRF method is adequate enough to analysis the heavy metal contents in moss samples even at very small concentration with high accuracy and precisely.
\end{abstract}

Key words: Heavy metals, contamination factor, terrestrial moss, petroleum industry

\section{INTRODUCTION}

The use of mosses as bio-monitors for environmental studies is growing in acceptance and become popular in environmental study (Raychaudhuri et al., 2008). Therefore, the implementation and improvement of suitable analytical tools to determine possibly low concentration of chemical composition in mosses matrices has become importance.

Techniques of sample analysis play very important role in environmental studies. They provide information on the chemical composition of substances and also facilitate the measurement of elements at major, minor and trace levels in various types of sample matrices. The modern analytical equipments have also enhanced the capabilities for the analysis of different types of matrices and the measurement of elements with more sensitivity, more accurate and low detection limits (ppm or $\mathrm{ppb}$ ). Therefore, in choosing the appropriate analytical technique, first task is to define the analytical problem, followed by the consideration of the factors like nature of sample, species to be analyzed and requirement of the analyst and the end use of the analytical results. It should also be kept in mind whether the information needed is qualitative or quantitative or maybe combination of them. For quantitative data, consideration is given to accuracy and precision, concentration range and detection limit of the expected variable, unique physical and chemical properties of the sample, nature of the matrix and the interferences that are likely to cause problems for the desired determinants (Margui et al., 2009).

Recently, analysis of environmental samples with X-Ray Fluorescence (XRF) techniques comply with

\section{Corresponding Author: Mohd Zahari Abdullah, Department of Chemistry, Faculty of Applied Sciences,}

University Technology MARA, 24600 Pahang, Malaysia 
desired features especially for the plants samples, including the multi-elemental capability, the possibility to perform qualitative and quantitative determinations, simple sample preparation prior to analysis, a wide dynamic range, high throughput and low cost predetermination. The main disadvantages of XRF technique are insufficient sensitivity for some important pollutants elements and somewhat related to worse precision and accuracy compared to the other atomic absorption spectroscopic techniques (Melquiades and Appoloni, 2004).

Nevertheless, the recent improvements in the XRF instruments such as the development of digital signal processing based spectrometers in combination with enlarge X-ray production using better designs for excitation-detection has added the advantage of increasing instrumental sensitivity, thus allowing the improvement of both precision and productivity. This fact has promoted an increasing interest of using X-ray techniques as an alternative to various types of destructive analytical methods to study environmental samples (Budak et al., 2006; Kalnicky and Singhvi, 2001; Hassan et al., 2007; Ekinci et al., 2004; Sonibare, 2005).

In this present study EDXRF spectrometer was optimized to evaluate the ability for analysis moss samples for heavy metals levels in the vicinity of oil refinery area. Some of the main analytical parameters of EDXRF technique were tested to minimize the possible random error and systematic error that possibly would influence the analytical results. To minimize the possible uncertainty of the quantitative analysis of this method, all the analytical steps involved starting with sample pre-treatment until to the calibration procedure were monitored and evaluated all the time. The optimized EDXRF then was used to measure the trace metals contents in the selected moss species Hypnum Plumaeforme as biomonitor to study the levels of these pollutants around oil refinery industrial areas. The implementation of modified analytical approach to evaluate the heavy metals contents in mosses using $\mathrm{XRF}$ spectrometer as analytical tools was discussed in details as one of the goals of this study.

\section{MATERIALS AND METHODS}

Sampling location: Moss samples were collected at 62 sampling stations surrounding the Petronas Carigali dan Penapisan (Terengganu) Sdn Bhd (an petroleum exploration and refinery plant). The petrochemical and petroleum industrial area is considered to be the pointed source of emission to surrounding atmosphere. The nearest sampling point was located about 500m away from boundary of the industrial precinct. Petroleum and petrochemical industrial area Kerteh is located in the east coast of Peninsular Malaysia within latitude $\mathrm{N} 04^{\circ}$ $31^{\prime}$ and longitude $103^{\circ} 27^{\prime} \mathrm{E}$, with temperate and climate influenced by the Southwest Monsoon (late May to September) and the Northeast Monsoon (November to March) that resulting heavy rainfall to the study area. The area is generally fairly hot and humid all year round, with temperature averaging from $28-30^{\circ} \mathrm{C}$ in daytime and slightly cooler after sunset.

Samples collection: Sampling technique and related procedures were based on the Scandinavian guidelines (Ruhling, 2002). In the particular sites where Hypnum Plumaeforme moss species was not available, Taxithelium Instratum moss species were collected. Sampling was performed in a relatively dry season within July and September 2009 to a total of 62 sampling stations. In a whole, the sampling location are scattered and not evenly distributed along $30 \mathrm{~km}$ surrounding the oil refinery industrial base. Sampling stations were not evenly distributed due to geographical problems and the availability of the particular moss species used in this study.

The geographic coordinates were determined using GPS. The sampling point locations were situated at least 50 meter away from main roads or buildings. Most of the samples were collected in an open area and from oil palm estates. At each site a few grams of sample was collected within an area of $50 \times 50 \mathrm{~m}^{2}$. The green or greenish-brown parts of the plant were (represent 3-5 years of growth) used for further analysis directly without washing or any other treatments.

Samples treatment: All kind of foreign materials adhering to the surface of the samples such as tree bark, lichens, soil dust and dead materials were removed thoroughly in dry condition. For the analysis, only the green and greenish brown parts of the moss plants were used, as they generally are intended to represent a period of about 3-5 years growth. Their metal content is generally considered to reflect the atmospheric deposition during that period (Wolterbeek, 2002). The samples were then oven dried at $60^{\circ} \mathrm{C}$ for $48 \mathrm{~h}$.

To reduce particle size and satisfy the conditions for homogeneity of the sample, the samples were ground in an agate ball mill using a grinding time in the range of 3-5 min at $300 \mathrm{rpm}$. Once moss tissues were powdered and dried, they were stored in capped polypropylene flasks until analysis. Prior analysis with 
EDXRF, about 2 spatulas of powdered moss sample (without the addition of a binder) was pressed at about 15 tons for 30 s to obtained cylindrical pellets.

Analytical technique: In general, XRF quantitative analysis is carried out by the calibration curve method, generated from many calibration standards. However, for mosses samples it is difficult to get the sufficient certified standards, with similar matrices to the real samples, in order to achieve a good spread of data points over the range of each element to be determined. However, the use of standards prepared in the laboratory with commercially available pure elements or compounds has been shown to be efficient for calibration purposes since they considered are inexpensive and can be easily prepared. Since mosses samples as a green plants consists mainly of $\mathrm{C}, \mathrm{N}, \mathrm{H}$ and O (Updegraff , 1969; Ino and Nakatsubo, 1986), the standard samples (in the form of pellet) have been prepared by dropping about $0.5 \mathrm{ml}$ of multi-elements standard solution onto a similar pellet size of Whatman 41 (cellulose filter) filter study. The filter study then has been dried in dry oven at $40^{\circ} \mathrm{C}$ for $12 \mathrm{~h}$. The calibration curves for all elements have been developed by using five series of standard samples with five different elemental concentrations. By doing this technique (using synthetic substrate of cellulose), we hope that it could provide a good means to simulate the mosses matrix and obtain reliable calibration curves with a good spread of data points over the range of each element to be determined.
The reliability of the optimized analytical procedure was established by analyzing two certified reference materials, Pine Needle, NIST 1575 a and Lichen, IAEA336. Eleven heavy metals were analyzed by using bench top PanAnalytical EDXRF spectrometer Model Minipal 4. With the aims to achieve the best performance of the EDXRF to analyzed moss samples, a few instrumental parameters of EDXRF were examined before being fully used to analyze the real moss samples. Three operational EDXRF parameters have been evaluated that comprises of X-ray detector filter (Mo, $\mathrm{Ag}$ and $\mathrm{Al}$ ), counting time and technique of peak intensity measurement.

\section{RESULTS}

Optimization of EDXRF spectrometer conditions: Selection of X-ray beam filter: Figure 1 show one of the best spectrum obtained for the 11 elements in a specific range of energies. The spectrum is the result from the application of $\mathrm{Ag}$ as a beam filter in the spectrometer. Meanwhile, the spectra obtained by the application of other two beam filter, Mo and $\mathrm{Al}$ (not included) show that the characteristic peaks were not fully separated while the background intensity of these spectra were not constant along the energy range of 2 $\mathrm{keV}-13 \mathrm{keV}$.

Measurement of peak intensity: Table 1 show the results of the evaluation of the two different peak measurement techniques. Based on the Table (measurement of peak intensity based on peak height), the high value of $\%$ RSD were observed for elements $\mathrm{V}, \mathrm{Cr}$ and Se with $7.09-6.53$ and $9.45 \%$ respectively.

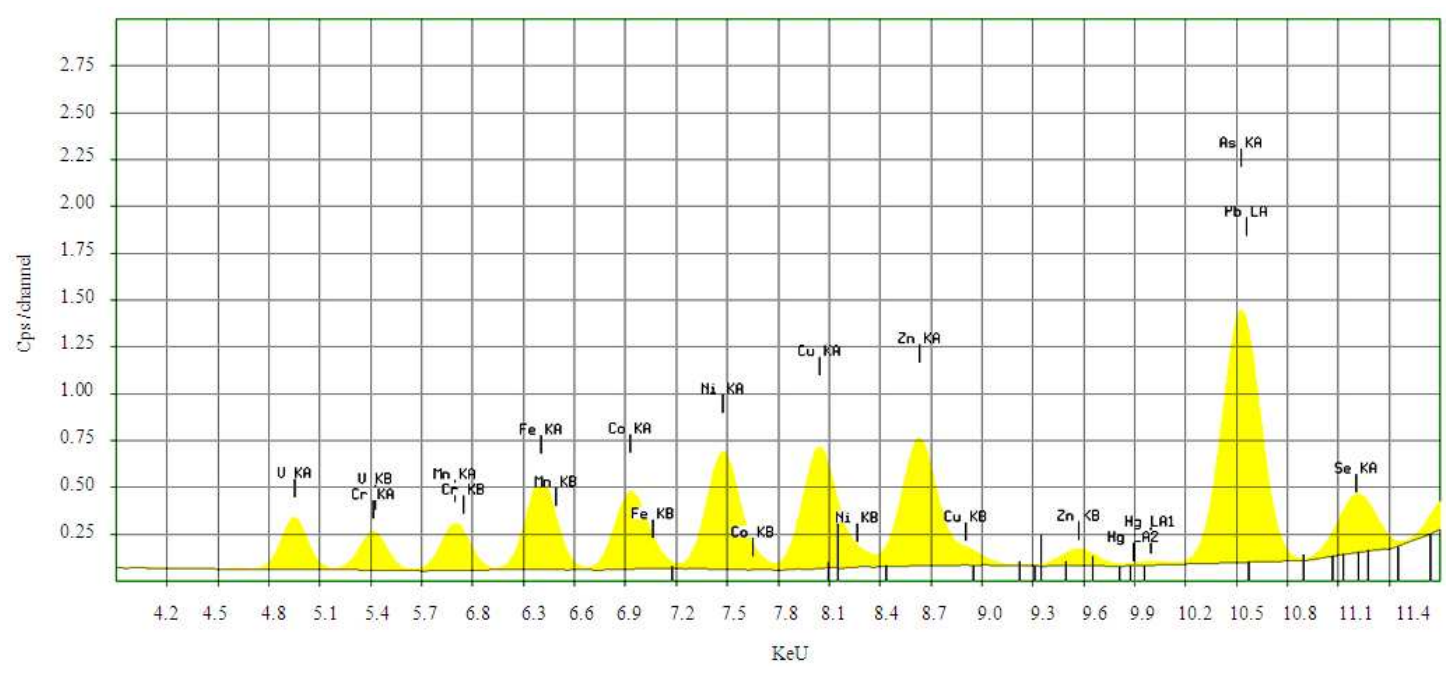

Fig. 1: EDXRF spectrum obtained by using Ag beam filter 
Am. J. Engg. \& Applied Sci., 4 (3): 355-362, 2011

Table 1: The results of peak intensity obtained from the analysis of standard sample (3 times replication)

\begin{tabular}{|c|c|c|c|c|c|c|c|}
\hline \multicolumn{4}{|c|}{ Intensity measured based on peak height } & \multicolumn{4}{|c|}{ Intensity measured based on net area } \\
\hline Metals & Mean intensity & Std deviation, $\sigma$ & $\operatorname{RSD}(\%)$ & Metals & Mean Intensity & Std deviation, $\sigma$ & $\operatorname{RSD}(\%)$ \\
\hline V & 0.31 & 0.022 & 7.09 & $\mathrm{~V}$ & 2.64 & 0.355 & 13.45 \\
\hline $\mathrm{Cr}$ & 0.26 & 0.017 & 6.53 & $\mathrm{Cr}$ & 1.58 & 0.182 & 11.52 \\
\hline $\mathrm{Mn}$ & 0.28 & 0.005 & 1.79 & $\mathrm{Mn}$ & 2.30 & 0.253 & 11.00 \\
\hline $\mathrm{Fe}$ & 0.48 & 0.015 & 3.13 & $\mathrm{Fe}$ & 4.17 & 0.167 & 4.000 \\
\hline $\mathrm{Co}$ & 0.44 & 0.023 & 5.30 & Co & 3.67 & 0.338 & 9.210 \\
\hline $\mathrm{Ni}$ & 0.59 & 0.040 & 6.78 & $\mathrm{Ni}$ & 5.44 & 0.512 & 9.410 \\
\hline $\mathrm{Cu}$ & 0.66 & 0.012 & 1.82 & $\mathrm{Cu}$ & 6.15 & 0.330 & 5.360 \\
\hline $\mathrm{Zn}$ & 0.72 & 0.036 & 5.00 & $\mathrm{Zn}$ & 7.26 & 0.175 & 2.410 \\
\hline As & 1.58 & 0.053 & 3.35 & As & 12.38 & 0.487 & 3.930 \\
\hline $\mathrm{Se}$ & 0.28 & 0.026 & 9.45 & $\mathrm{Se}$ & 2.69 & 0.179 & 6.630 \\
\hline $\mathrm{Pb}$ & 1.21 & 0.006 & 0.49 & $\mathrm{~Pb}$ & 7.25 & 0.688 & 9.490 \\
\hline
\end{tabular}

Table 2: Peak intensities (counts/second) obtained when the same moss sample were analyzed with EDXRF spectrometer for 3 different counting times

\begin{tabular}{|c|c|c|c|c|c|}
\hline Metals & $\begin{array}{l}\text { Intensity Counts/s } \\
100 \mathrm{~s}\end{array}$ & $\begin{array}{l}\text { Intensity Counts/s } \\
200 \mathrm{~s}\end{array}$ & $\begin{array}{l}\text { Intensity Counts/s } \\
300 \mathrm{~s}\end{array}$ & Mean & $\operatorname{RSD}(\%)$ \\
\hline $\mathrm{V}$ & 7.30 & 7.62 & 7.12 & 7.35 & 3.45 \\
\hline $\mathrm{Cr}$ & 1.93 & 2.23 & 2.01 & 2.06 & 7.55 \\
\hline $\mathrm{Mn}$ & 12.19 & 11.81 & 12.22 & 12.07 & 1.89 \\
\hline $\mathrm{Fe}$ & 1567.00 & 1567.00 & 1568.00 & 1567.33 & 0.04 \\
\hline Co & 19.98 & 19.81 & 20.12 & 19.97 & 0.78 \\
\hline $\mathrm{Ni}$ & 7.19 & 6.25 & 6.88 & 6.77 & 7.07 \\
\hline $\mathrm{Cu}$ & 9.81 & 9.38 & 9.66 & 9.62 & 2.27 \\
\hline $\mathrm{Zn}$ & 21.76 & 22.31 & 21.22 & 21.76 & 2.50 \\
\hline As & 33.26 & 33.76 & 32.19 & 33.07 & 2.43 \\
\hline $\mathrm{Se}$ & 7.83 & 7.95 & 7.72 & 7.83 & 1.47 \\
\hline $\mathrm{Hg}$ & 2.02 & 1.47 & 2.51 & 2.41 & 3.94 \\
\hline $\mathrm{Pb}$ & 24.88 & 25.30 & 26.13 & 25.44 & 2.50 \\
\hline
\end{tabular}

Table 3: Blank sample concentration and Limit of Detection for 11 metals analyzed with EDXRF (LOD for each element has been considered as $3 \sigma$ )

\begin{tabular}{llll}
\hline Metal & $\begin{array}{l}\text { Mean concentration, } \\
\mu \mathrm{g} \mathrm{g}^{-1} \text { dry wt }\end{array}$ & $\begin{array}{l}\text { LOD } \\
\mu \mathrm{g} \mathrm{g}^{-1} \text { dry wt }\end{array}$ & Differences (\%) \\
\hline $\mathrm{V}$ & 0.323 & 0.075 & 76.78 \\
$\mathrm{Mn}$ & 2.300 & 1.070 & 53.48 \\
$\mathrm{Fe}$ & 7.467 & 1.212 & 83.77 \\
$\mathrm{Ni}$ & 3.217 & 1.189 & 63.05 \\
$\mathrm{Cu}$ & 1.907 & 0.609 & 68.07 \\
$\mathrm{Cr}$ & 0.980 & 0.420 & 57.14 \\
$\mathrm{Zn}$ & 1.137 & 0.183 & 83.91 \\
$\mathrm{Hg}$ & 0.100 & 0.060 & 40.00 \\
$\mathrm{~Pb}$ & 0.153 & 0.035 & 77.13 \\
$\mathrm{As}$ & 0.280 & 0.120 & 57.14 \\
$\mathrm{Se}$ & 0.703 & 0.478 & 32.01 \\
\hline
\end{tabular}

The optimized counting time: Table 2 shows the results obtained when a series of counting time 100s, 200s and 300s have been evaluated.

The applications of three different counting times have produced no significant differences of the peak intensities values in this study. The peaks spectrum obtained show that the variances of measured peak intensities are in the range of $0.0 \%$ for $\mathrm{Fe}$ and $7.55 \%$ for $\mathrm{Cr}$. The overall intensities observed in this study clearly shows that the quantitative analysis of metals concentration by EDXRF technique are not much depends on its counting times. Therefore, 100s counting time has been considered as the adequate time for the analysis of moss sample by EDXRF in this study.

Limit of detection, LOD: LOD for each interested heavy metal in the analysis. Are shown in Table 3 . The table shows the results of metals concentration obtained when the blank cellulose filter (considered as the background matrix) were analyzed by EDXRF technique. The standard deviations for each metal were then has been calculated based on blank samples concentration (considered as having lower metal concentration).

The results of LOD obtained in this study clearly show that each element in this study has a different LOD value that ranging from the lowest for $\mathrm{Pb}$ with $0.035 \mu \mathrm{g}$ $\mathrm{g}^{-1}$ and the highest for Fe with $1.212 \mu \mathrm{g} \mathrm{g}^{-1}$. Therefore, the contents of elements in mosses should not exceed with these LOD values for all the studied elements.

Validation of the analytical technique: Standard reference material, SRM was analyzed in parallel with metal determinations. Result from the analysis of SRM was used to evaluate the reliability and accuracy of the adopted in this study. 
Am. J. Engg. \& Applied Sci., 4 (3): 355-362, 2011

Table 4: Mean concentrations $\left(\mu \mathrm{g} \mathrm{g}^{-1}, \mathrm{n}=3\right.$ ), \% recoveries and t-test value of selected elements found in Pine Needle, NIST 1575 a analyzed by EDXRF Spectrometer

\begin{tabular}{|c|c|c|c|c|}
\hline Metal & $\begin{array}{l}\text { Measured value, } \\
\mathrm{mg} \mathrm{kg}^{-1} \text { dry wt }\end{array}$ & $\begin{array}{l}\text { Certified value } \\
\mathrm{mg} \mathrm{kg}^{-1} \text { dry wt }\end{array}$ & Recoveries (\%) & $\begin{array}{l}\text { Statistic test } \\
\text { value, t-test }\end{array}$ \\
\hline $\mathrm{V}$ & $0.35 \pm 0.170$ & 0.340 & 102.940 & 0.10 \\
\hline $\mathrm{Mn}$ & $496.59 \pm 17.64$ & 488.000 & 101.760 & 0.84 \\
\hline $\mathrm{Fe}$ & $43.34 \pm 1.540$ & 46.000 & 94.220 & 2.90 \\
\hline $\mathrm{Ni}$ & $1.34 \pm 0.100$ & 1.470 & 91.160 & 1.40 \\
\hline $\mathrm{Cu}$ & $2.42 \pm 0.410$ & 2.890 & 83.740 & 1.60 \\
\hline $\mathrm{Cr}$ & $0.35 \pm 0.130$ & 0.400 & 87.500 & 0.68 \\
\hline $\mathrm{Zn}$ & $36.65 \pm 1.100$ & 38.000 & 96.450 & 2.12 \\
\hline $\mathrm{Hg}$ & $0.040 \pm 0.01$ & 0.039 & 102.560 & 0.17 \\
\hline $\mathrm{Pb}$ & $0.17 \pm 0.020$ & 0.167 & 101.780 & 0.25 \\
\hline As & $0.04 \pm 0.010$ & 0.039 & 102.560 & 0.17 \\
\hline $\mathrm{Se}$ & $0.26 \pm 0.020$ & - & - & - \\
\hline
\end{tabular}

Note: The sign of- indicates that the elements are not certified

Table 5: Mean concentrations $\left(\mu \mathrm{g} \mathrm{g}^{-1}, \mathrm{n}=3\right), \%$ recoveries and t-test value of selected elements found in Lichen, IAEA-336 analyzed by edxrf Spectrometer

\begin{tabular}{|c|c|c|c|c|}
\hline Metal & $\begin{array}{l}\text { Measured value, } \\
\mathrm{mg} \mathrm{kg}^{-1} \text { dry wt }\end{array}$ & $\begin{array}{l}\text { Certified value } \\
\mathrm{mg} \mathrm{kg}^{-1} \text { dry wt }\end{array}$ & Recoveries (\%) & $\begin{array}{l}\text { Statistic test } \\
\text { value, t-test }\end{array}$ \\
\hline $\mathrm{V}$ & $2.05 \pm 0.29$ & - & - & \\
\hline $\mathrm{Mn}$ & $63.96 \pm 3.32$ & 63.00 & 101.52 & 0.50 \\
\hline $\mathrm{Fe}$ & $411.30 \pm 4.02$ & 430.00 & 95.65 & 8.06 \\
\hline $\mathrm{Ni}$ & $0.50 \pm 0.02$ & - & - & - \\
\hline $\mathrm{Cu}$ & $3.43 \pm 0.58$ & 3.60 & 95.28 & 0.51 \\
\hline $\mathrm{Cr}$ & $0.98 \pm 0.08$ & 1.06 & 92.45 & 1.78 \\
\hline $\mathrm{Zn}$ & $34.67 \pm 0.79$ & 30.40 & 114.05 & 9.36 \\
\hline $\mathrm{Hg}$ & $0.25 \pm 0.02$ & 0.20 & 125.00 & 4.33 \\
\hline $\mathrm{Pb}$ & $4.70 \pm 0.05$ & 4.90 & 95.92 & 6.93 \\
\hline As & $0.76 \pm 0.06$ & 0.63 & 120.63 & 3.75 \\
\hline $\mathrm{Se}$ & $0.24 \pm 0.10$ & 0.22 & 109.09 & 0.35 \\
\hline
\end{tabular}

Note: The sign of- indicates that the elements are not certified

Two different SRM have been analyzed, Pine Needle (Nist 1575a) and Lichen (IAEA 336). The results of the determined concentration of interested elements were presented in Table 4 and 5. The results obtained show that the metals could be analyzed with percent recoveries range within $84-102 \%$ for Pine Needle and $92-125 \%$ for Lichen.

\section{DISCUSSION}

The way how the intensity of each peak in the Xray spectra is measured is considered as one of the major step that should be evaluated and optimized. Since XRF is a comparative technique where the measured intensity of an analyte peak is related to its concentration, the peak intensity must be correctly measured. By determining the best net peak intensities for standards, a calibration curve can be drawn and a slope could be determined. The overall accuracy of any XRF analysis therefore depends on the accuracy of the peak and background measurements as well as the accuracy of the slope derived from the calibration curve. The measurement intensities based on net peak in this study has give the results with random errors in the range of $2.03-13.45 \%$. The results clearly show that the low concentration elements such as $\mathrm{V}, \mathrm{Cr}, \mathrm{Mn}, \mathrm{Pb}, \mathrm{Ni}$ and Co were measured with \% RSD higher than $10 \%$ (not consistence). Meanwhile, the measurements of peak intensities of $\mathrm{Zn}$ and $\mathrm{Fe}$ give more consistent values where the $\%$ RSD were recorded less than $4 \%$. With the above observations, it is proven in this study that the measurement of peak spectrum intensities through peak height has deliver more consistent results compared to the measurement based on net peak.

It is a vital step to decide the best way how the peak intensity should be measured. Based on the relative standard deviation, RSD values, both measuring techniques show a comparable random error during the intensities measurement being taken. Normally these kinds of errors (random) are difficult to be controlled. The high values of these elements indicate that the peak intensities measurement for these three elements were less $10 \%$ inconsistent. While, $\mathrm{Pb}$ metal has the lowest value of $\%$ RSD with $0.49 \%$ which indicates that the measurement of height of $\mathrm{Pb}$ peak was almost consistent for all $\mathrm{Pb}$ spectra. For the other nine elements, the variances of peak intensities measurements are fall within $1.79-6.78 \%$.

The standard factor for selecting the appropriate counting time is precision. Most operators will use measurement times from $10 \mathrm{sec}$ to ten min. Shorter 
count times 10-30 sec are used more for qualitative scanning and sorting. In the laboratory a good practice is to count for as long as appropriate time. Generally, the concentration range of the elements of interest is played an important factor. Major elements in percent concentrations can be analyzed in a minute or less, while minor elements at $\mu \mathrm{g} \mathrm{g}^{-1}$ concentration may need to be analyzed for 3-10 min. or longer. It's depends on the sensitivity of the specific EDXRF instrument.

LOD as a guideline, we can claim that the element is present in the analyzed sample if its concentration is greater than this limit value for a particular element. LOD values also can be used to evaluate whether the instrument is sensitive enough to detect all the concentration range of the elements to be determined. The most current detection limit used in XRF analysis is the lower limit of detection which is assumed to be the concentration equivalent to three standard counting errors (deviation) of a set of measurements of the background intensity (Rousseau, 2001).

The LOD is defined as being the lowest net peak intensity of an analyte, expressed in concentration unit that can be detected by an instrument in a given analytic context with a $95 \%$ confidence level. In this study, the LOD is measured as equal to 3 times the standard counting error of the background intensity. The LOD determined by this way is sometimes called instrument limit of detection because it is not only a estimation of minimum detectable but it takes into account the instrument characteristics and sample matrix.

The results of accuracy can be interpreted in several of ways. In this study, statistically, the accuracy test was made by comparing the values of metal concentration obtained in this study with certified values. The accuracy of the results was explained through analyzing the percentage of recoveries between analyzed and certified values as shown in Table 4 and Table 5. It shows that, for Pine Needle (NIST 1575 a), good to excellent recoveries ranging from 83.74$102.94 \%$ were obtained for the studied elements indicating good overall accuracy of the applied method. While for Lichen (IAEA 336), the \% recoveries are in the range of $82.86-120.63 \%$. It is assumed from this study that sample matrix of mosses has plays an importance factor to influence the high recoveries for $\mathrm{Hg}$ and As from standard material of Lichen.

Statistical test like student t-test normally also can be used to evaluate the precision of an analytical method applied. Determining the value of this statistical test is based on the mean concentration of metals, standard deviation and the certified values. T-test values obtained for each single element then compared with the t-test value (Table t-test) at 5\% confidence level.

Comparing the t-test values for metals obtained in this study and the values stated in certificate (4.3), it was found that there were no statistically significant differences in the 5\% confidence level for SRM Pine Needle 1575 a. Meanwhile for Lichen 336, it was found that the concentration of elements of $\mathrm{Fe}, \mathrm{Zn}, \mathrm{Hg}, \mathrm{Pb}$ and As were significantly difference at the confidence level of 5\% compared to the certified values. Nevertheless, all the metals analyzed in SRM Lichen were found precise at $1 \%$ confidence level. Sometime, the poor precision of analytical technique applied would be observed due to very low concentration of the interested elements in particular samples analyzed. With all these observations, it can be concluded that the application of optimized EDXRF approach in this study are adequate to analyze moss samples with high percentage recoveries.

Classification of the pollutants levels in the study areas: CFs scales were used to interpret the results of CFs values obtained in this study. The scale is based on the similar one that has been proposed by Fernandez and Carballeira (2001). For more specific approach to terrestrial mosses, Fernandez et al. (2000) has established a scale that allows categorization of determined sampling sites in terms of the CF values for each element while taking into account the method of dispersion of contaminants in the atmosphere. By using this scale, it is possible to interpret the results obtained from the analysis of moss samples.

With considering there are multiple sources of emission: elevated sources (chimneys), ground-level sources (industrial areas), regional sources (agricultural activities) and also linear sources (road and traffic), the scale of classification has been developed by assuming that the dispersion pattern was similar in all cases. The scale of contamination factors and its descriptive statement is shown in Table 6. Meanwhile, the results of the calculated CFs values for all elements in all sampling stations are shown in Table 7.

Table 6: Contamination scale of heavy metals

\begin{tabular}{lll}
\hline CFs value scale & Classification & Contamination \\
\hline 1 and less & No contamination & C1 \\
$1-2$ & Suspected & C2 \\
$20-3.5$ & Slight & C3 \\
$3.5-8$ & Moderate & C4 \\
$8-27$ & Severe & C5 \\
27 and above & Extreme & C6 \\
\hline
\end{tabular}


Am. J. Engg. \& Applied Sci., 4 (3): 355-362, 2011

Table 7: The number of sampling stations (\%) that have been classified based on the six contamination scales for 11 elements in the analyzed moss samples

\begin{tabular}{|c|c|c|c|c|c|c|}
\hline Category & C1 (\%) & $\mathrm{C} 2(\%)$ & C3 (\%) & $\mathrm{C} 4(\%)$ & C5 (\%) & C6 $(\%)$ \\
\hline V & 0.0 & 1.5 & 9.5 & 42.0 & 47.0 & 0.0 \\
\hline $\mathrm{Cr}$ & 1.5 & 1.5 & 3.2 & 34.9 & 55.0 & 3.2 \\
\hline $\mathrm{Mn}$ & 6.5 & 24.2 & 21.6 & 40.3 & 8.1 & 0.0 \\
\hline $\mathrm{Fe}$ & 1.6 & 4.0 & 16.1 & 53.2 & 25.8 & 0.0 \\
\hline $\mathrm{Hg}$ & 0.0 & 1.6 & 14.3 & 65.7 & 17.5 & 0.0 \\
\hline $\mathrm{Ni}$ & 8.0 & 31.7 & 37.1 & 24.2 & 1.6 & 0.0 \\
\hline $\mathrm{Cu}$ & 28.6 & 40.0 & 1.6 & 23.8 & 0.0 & 0.0 \\
\hline $\mathrm{Zn}$ & 8.0 & 28.6 & 28.6 & 30.2 & 3.2 & 0.0 \\
\hline As & 0.0 & 9.5 & 22.2 & 51.0 & 15.9 & 0.0 \\
\hline $\mathrm{Pb}$ & 6.3 & 27.0 & 27.0 & 38.1 & 0.0 & 0.0 \\
\hline $\mathrm{Se}$ & 0.0 & 0.0 & 3.2 & 3.2 & 69.8 & 22.2 \\
\hline
\end{tabular}

Note: The \% value indicates the total number of sampling sites that recorded a specific CFs value (1 to 27 and above) out of 62 overall sampling stations in percentage

The evaluation of the CFs results indicate that the first two categories of scale, $\mathrm{C} 1$ and $\mathrm{C} 2$ are described as uncontaminated (a $\mathrm{CF}$ of 2 can easily obtained from natural variation), depended on the metal considered. By examining the CFs data of each element as shown in Table 7, there are a few observations can be made. From all of the 11 elements, there are a few metals that were not significantly contaminated. For $\mathrm{Cu}$, around $70 \%$ of the studied areas were included in the first two categories (C1 and C2). Therefore, only 30\% out of 62 sampling stations have been contaminated with $\mathrm{Cu}$ (below 2 times exceeding the background value). The CFs values that exceeding the cut point of 3 and above $(30 \%)$ are scattered mostly in the northwest and northern parts of the main point of emission.

Among the metals that had recorded a relatively high percentage of categories $\mathrm{C} 1$ and $\mathrm{C} 2$ were $\mathrm{Mn}$ (30.7 $\%)$, Ni (39.7\%), Zn (36.6\%) and $\mathrm{Pb}(33.3 \%)$ while V, $\mathrm{Cr}, \mathrm{Fe}, \mathrm{Hg}, \mathrm{As}$ and $\mathrm{Se}$ have recorded less than $10 \%$ out of 62 overall sampling stations. Based on the relatively low percentage of these elements for categories $\mathrm{C} 1$ and $\mathrm{C} 2$, it was strongly suggested that these elements (V, $\mathrm{Cr}, \mathrm{Fe}, \mathrm{Hg}$, As and $\mathrm{Se}$ ) are highly associated with the anthropogenic sources or manmade activities.

Very significant contamination were observed for $\mathrm{V}, \mathrm{Cr}, \mathrm{Fe}, \mathrm{Hg}, \mathrm{As}$ and Se where almost over $70 \%$ out of the total sampling stations for these elements were included in the categories C4 and C5. By definition, categories of $\mathrm{C} 4$ and $\mathrm{C} 5$ indicate that the particular element present in moss samples at concentration ranging from 4-27 times higher than the background readings that obtained in mosses from remote area. Therefore the sites were categorized as clearly have been contaminated by these elements. It was not possible to distinguish between metals usually associated with the lithology (such as $\mathrm{Cr}$ and $\mathrm{Fe}$ ) or importance of plants such as $\mathrm{Mn}, \mathrm{Cu}$ and $\mathrm{Zn}$ with typical contaminants such as $\mathrm{V}, \mathrm{Pb}$ and $\mathrm{Ni}$. Furthermore, the metals that is important for soil dust or
All of the CFs data obtained have been compared to the CFs scale by means to evaluate the status of the existence of these 13 heavy metals around the study area has made the area being polluted or not crustal association, such as $\mathrm{Se}$ and $\mathrm{Fe}$ do not show comparable results. Because of that where sometime the results were not consistent, classification of sites cannot be interpreted straightforward from the CFs values where a few more parameters such as enrichment factor and multivariate analysis are needed to strengthen the information before any site interpretation and classification could be made.

\section{CONCLUSION}

By considering of the above particular points especially regarding to the detection limits, precision, accuracy and spectral information obtained in this study, it strongly believed that EDXRF method were highly suitable to analyzed moss samples. Combination of plants certified reference materials and laboratory synthetic calibrators made of cellulose to simulate the real moss matrix appears to be an effective means to obtain reliable calibration curves with a good spread of data points over the range of interested elements to be determined. Results obtained from the quantitative study clearly show the linearity over the whole concentration range of each element. EDXRF technique was also well suited for multi-element determinations for environmental samples where the characteristic peaks easily to be separated and identified. In particular, the samples do not need any chemical pretreatment and no binding agents are needed to form a pellet sample and this could eliminate any possibility of contamination. The samples are analyzed nondestructively, being retained for reused for further studies. The small sample size required, coupled with its other good features make it a valuable instrument for environmental studies. 
Generally, from this present study we have found that the study areas were not severely contaminated with the studied heavy metals. Most of the studied heavy metals were found accumulated in the moss samples in acceptable concentration levels that expected would not harm the surrounding living organism except for elements Se and $\mathrm{Cr}$. The fairly high of these two elements accumulated in moss sample probably were influenced by the oil refinery activities in this area especially for $\mathrm{Cr}$ which normally their existence were attributed to the fuel combustion activities. From this preliminary study, it could be concluded that the oil refinery activity in the area has played an important role for the elevation of certain elements in moss sample in the study areas.

\section{ACKNOWLEDGMENT}

The researches would like to express their deeply appreciation to UITM Malaysia especially RMI UITM for the financial supports and all individuals for their assistant and recommendation.

\section{REFERENCES}

Budak, G., I. Aslan, A. Karabulat and E. Tirasoglu, 2006. Analysis of some elements in three Chrysolina (Coleoptera, Chrysomelidae) species by EDXRF spectrometry. J. Quan. Spect. Radiative Transfer, 101: 195-200. DOI: 10.1016/J.JQSRT.2005.11.013

Ekinci, N., R. Ekinci, R. Polat and G. Budak, 2004. Analysis of trace elements in medicinal plants with energy dispersive X-ray fluorescence. J. Radioanalytical Nuclear Chem., 260: 127-131. DOI: 10.1023/B:JRNC.0000027071.72742.ee

Fernandez, J.A., A. Rey and A. Carballeira, 2000. An extended study of heavy metal deposition in Galicia (NW Spain) based on moss analysis. Sci. Total, Environ., 254: 31-44. DOI: 10.1016/S00489697(00)00431-9

Fernandez, J.A. and A. Carballeira, 2001. Evaluation of contamination, by different elements, in terrestrial mosses. Arch. Environ. Contam. Toxicol. 40: 461468. DOI: $10.1007 / \mathrm{s} 002440010198$
Hassan, N.M., P.E. Rasmussen, E. Dabek-Zlotorzynska and H. Chen, 2007. Analysis of environmental samples using microwave-assisted acid digestion and inductively coupled plasma mass spectrometry: Maximizing total element recoveries. Water Air Soil Pollut., 178: 323-334. DOI: 10.1007/s11270006-9201-3

Ino, Y. and T. Nakatsubo, 1986. Distribution of carbon, nitrogen and phosphorus in a moss community-soil system developed on a cold desert in Antarctica. Ecol. Res., 1: 59-69. DOI: 10.1007/BF02361205

Kalnicky, D.J. and R. Singhvi, 2001. Field portable XRF analysis of environmental samples. J. Hazardous Mater., 83: 93-122. DOI: 10.1016/S03043894(00)00330-7

Margui, E., I. Queralt and M. Hidalgo, 2009. Application of X-ray fluorescence spectrometry to determination and quantitation of metals in vegetal material. Trend Anal. Chem., 28: 362-372. DOI: 10.1016/j.trac.2008.11.011

Melquiades, F.L. and C.R. Appoloni, 2004. Application of XRF and field portable XRF for environmental analysis. J. Radioanalytical Nuclear Chem., 262: 533541. DOI: 10.1023/B:JRNC.0000046792.52385.b2

Raychaudhuri, S., M. Mishra, S. Salodkar, M. Sudarshan and A.R. Thaku, 2008. Traditional aquaculture practice at east Calcutta wetland: The safety assessment. Am. J. Environ. Sci., 4: 173-177. DOI: 10.3844/ajessp.2008.173.177

Rousseau, R.M., 2001. Detection limit and estimate of uncertainty of analytical XRF results. Rigaku J., 18: 33-47.

Ruhling, A., 2002. A European survey of atmospheric heavy metal deposition in 2000-2001. Environ. Pollut., 120: 23-25. DOI: 10.1016/S02697491(02)00125-2

Sonibare, J.A., F.A. Akeredolu, O. Osibanjo and I. Latinwo, 2005. ED-XRF analysis of total suspended particulates from enamelware manufacturing industry. Am. J. Applied Sci., 2: 573-578. DOI: 10.3844/ajassp.2005.573.578

Updegraff, D.M., 1969. Semimicro determination of cellulose inbiological materials. Analytical, Biochem., 32: 420-424. DOI: 10.1016/S0003-2697(69)80009-6

Wolterbeek, B., 2002. Biomonitoring of trace element air pollution: Principles, possibilities and perspectives. Environ. Pollut., 120: 11-21. DOI: 10.1016/S02697491(02)00124-0 